\title{
El tratamiento de los gentilicios en el Diccionario panhispánico de dudas
}

\author{
ENCARNACIÓN TABARES PLASENCIA
}

Universität Leipzig

\section{INTRODUCCIÓN}

\subsection{Introducción: Precedentes del Diccionario panhispánico de dudas}

Como indica Ahumada (2012: 56-58), el tratamiento en torno a la corrección o la incorrección lingüísticas no es un contenido habitual en los diccionarios generales durante los siglos que preceden a los diccionarios de dudas. Esta cuestión era objeto de las gramáticas. Y esto es constatable desde Nebrija (1984 [1492]) a Benito de San Pedro (1769). Así pues, Nebrija incluye al final de su gramática un capítulo dedicado a los barbarismos y solecismos en relación con la sintaxis del castellano. Por su parte, Correas (1903 [1626]: 251) también se refiere a los «vicios capitales del habla» y menciona como tales la barbariedad, escuridad y desorden, siendo que el barbarismo y el solecismo serían, para el gramático, especies de la barbariedad.

Con la llegada de la dinastía borbónica a España, lo francés lo impregna todo y, en tal ambiente, nace el Diccionario de Autoridades y el Diccionario castellano de Terreros. Pero más próximos a los que luego serán los diccionarios de dificultades o de dudas, habría que situar algunas obras lexicográficas con gran vocación normativa que comienzan a proliferar, sobre todo, a partir del siglo XIX y en las primeras décadas del XX, muchas de ellas asociadas al ámbito regional hispánico (Ahumada 2012: 58 y ss.). Así, pueden citarse Corrección de lenguaje ó sea Diccionario de disparates que contiene más de mil y cien palabras mal dichas, con su oportuna corrección, acompañadas de algunos arcaísmos y locuciones ridículas, de Francisco Antolín y Sáez (1867); Cizaña del lenguaje: Vocabulario de disparates, extranjerismos, barbarismos y demás corruptelas, pedanterías y desatinos introducidos en la lengua castellana (Q.E.P.D.) recopilados de muchos periódicos políticos y literarios, novelas y libros más o menos científicos, discursos académicos y parlamentarios, documentos oficiales y anuncios particulares de José Francisco Orellana (1891); Vicios del lenguaje y Provincialismos de Guatemala de Batres Jáuregui (1892); Diccionario manual de locuciones viciosas y de correcciones de lenguaje con indicación del valor de algunas palabras y ciertas nociones gramaticales de Ortúzar (1893); Serie de barbarismos, solecismos, aldeanismos y provincialismos que se refieren especialmente al vulgo tinerfeño, coleccionados $y$ traducidos al lenguaje corriente con notas explicativas y comprobativas de Reyes Martín (1918), entre otros.

ENCARNACIÓN TABARES PLASENCIA, «El tratamiento de los gentilicios en el Diccionario panhispánico de dudas», Revista de Lexicografia, XX (2014), pp. 167-186 Fecha de presentación: 05/11/2014 Fecha de aceptación: 12/03/2015 
Los diccionarios de dificultades no aparecen, sin embargo, como tal, hasta mediados del siglo XX, con el llamado Diccionario de dificultades de la lengua española de Díaz-Retg (1951), al que le seguirá, en esta misma estela, el Diccionario de dudas y dificultades de la lengua española de Seco, sin parangón hasta ese momento, puesto que, como bien dice Ahumada: «El mercado editorial de entonces ofrecía un nuevo producto lexicográfico que aunaba magistralmente en un mismo repertorio la tradición de los diccionarios de correcciones y la novedad de los diccionarios de dificultades» (2002: 65).

Con posterioridad, han ido apareciendo otras obras lexicográficas que o bien se mantienen en la línea prescriptivista de los antiguos diccionarios de «incorrecciones»o bien, con mayor o menor fortuna, han intentado seguir la senda abierta por los diccionarios de dudas y dificultades de la lengua o han aunado ambos aspectos. Remito al detallado catálago de productos lexicográficos hasta el año de edición de su obra que nos ofrecen Haensch y Omeñaca (2004: 133-135). Estos autores mencionan separadamente, además, otros trabajos como manuales de español correcto o gramáticas donde se incluyen apartados dedicados al léxico. En octubre del año 2005, como todos sabemos, aparece publicado el Diccionario panhispánico de dudas, después de que su texto fuera aprobado un año antes, concretamente el 13 de octubre de 2004, en una sesión plenaria conjunta de la Real Academia Española y la Asociación de las 22 Academias de la Lengua Española.

\subsection{Fortunas y miserias del Diccionario panhispánico de dudas}

Desde su publicación en el año 2005, el Diccionario panhispánico de dudas (en adelante, DPD) ha sido objeto de una profunda exégesis y ha gozado de tantas alabanzas como críticas. Así, Vergara Silva (2005: 145-147) destaca su carácter panhispánico, logrado, según su opinión, por la estrecha colaboración de las Real Academia Española y de las Academias americanas, así como su vocación plural, es decir, que pueda ser consultada por el mayor número de personas (docentes, investigadores, gente común, etc.).

Casales, en relación con la política lingüística del DPD señala que «[1]a política lingüística subyacente a la obra prioriza los factores implícitos de integración lingüística por encima de los explícitos que constituyen los procesos de normativización».

Por su parte, Gómez Torrego (2009 y 2012) resalta también la panhispanidad del diccionario, señalando que es la primera obra académica claramente panhispánica y que otras posteriores como la Nueva Gramática de la lengua española y la Ortografía han seguido la senda marcada por aquella. Pero no se queda ahí, ya que se encarga de enumerar todas sus «bondades» - en muchos casos, desde una perspectiva bastante etnocéntrica, de hablante de español europeo-, comenzando por mencionar que, cuando se publicó por primera vez, llenó un vacío normativo existente desde el año 1931, en que salio a la luz la última Gramática académica hasta ese momento. Igualmente, la obra habría servido, según Torrego, para superar la supuesta arbitrariedad académica, puesto que en ella se justificarían todos los fenómenos que se recogen, produciéndose una simbiosis entre lo normativo y lo científico. A su vez, buscaría la 
regularización del sistema, evitando el mayor número de excepciones y acercaría a los usuarios a las normas cultas americanas, dándose incluso preferencia a estas por ser mayor el número de hispanohablantes. Otro acierto, a decir del autor, sería la manera en que ha tratado los numerosos extranjerismos, sobre todo anglicismos.

Otros autores, sin embargo, se han mostrado muy críticos, no solo con el planteamiento general de la obra, sino también en lo que se refiere al tratamiento de cuestiones concretas como el papel de la diacronía en el diccionario, el género y el número de determinados vocablos, los extranjerismos, cultismos, topónimos y gentilicios.

Muy crítico se muestra Martínez de Sousa (2005). A este lingüista le resulta raro que se presente como normativa una obra que, por definición, no debería serlo; y que, siendo una obra normativa, indique que sean «igualmente correctas» dos o más formas diferentes. Entiende el autor, en este mismo sentido, que el consultante de este tipo de obras busca una solución y no que se le ofrezcan distintas posibilidades igualmente válidas. Esto genera más confusión y estupefacción que alivio. En cuanto a la pregunta de quién es su destinatario, Martínez de Sousa llega a la conclusión de que no puede tratarse del público en general sino profesionales, dado que el lenguaje utilizado, la terminología, etc. tienen una complejidad que así lo determinan. Tras estas críticas de carácter general, el autor se refiere a las carencias y desaciertos de la obra en el tratamiento de la ortografía, los extranjerismos, el género y número, los topónimos y gentilicios.

Pérez-Salazar Resano (2008), planteándose revisar cómo resuelve el DPD el hecho de tener en cuenta una pluralidad de normas dentro del español y comprobar si se puede generar desde esa postura el ideal de buen uso, la autora reseña elementos positivos de la obra, como su estructura y su intento de hacerla accesible a todo tipo de público; sin embargo, de la misma manera y en la línea de Martínez de Sousa, critica el hecho de que este esfuerzo por acercar la obra al público no versado en temas lingüísticos sea, muchas veces, vano. Remito a los acertados ejemplos que propone la autora y que desvirtúan la pretendida «democracia lingüística» del DPD (Pérez-Salazar Resano 2008: 60-62). La autora reprueba la postura ambigua del DPD, situado entre la orientación y el precepto, muchas veces. Interesantes resultan sus palabras en cuanto a los conceptos de «incorrección» y «agramaticalidad» empleados en la obra (Pérez-Salazar Resano 2008: 64). De la misma forma, Pérez-Salazar Resano (2008: 68-76), destaca críticamente la falta de precisión y sistematicidad al intentar integrar las distintas formas de variación (diatópica, diastrática y diafásica) en el diccionario. Todo ello le lleva a concluir que el DPD no es lo normativo que debiera ni permite el acercamiento de todo tipo de usuarios, además de ser poco sistemático en el tratamiento de los temas que propone (Pérez-Salazar Resano 2008: 77-78).

Tras este brevísimo repaso por parte de la bibliografía en torno al DPD, parece que, aunque se puede hablar de auténticos aciertos, siquiera desde el punto de vista teórico, en el sentido de querer ser una obra integradora (no solo de la variedad geográfica sino también social y contextual), situar la norma en el ámbito del uso, lo cierto es que los desaciertos e incoherencias metodológicas le restan utilidad a esta obra académica. Creo que es necesario tener en cuenta todos estos puntos de fricción porque tienen también su peso en el tratamiento que se hace en el diccionario de los gentilicios, a los 
que me dedicaré ahora, no sin antes, hablar brevemente del concepto de gentilicio y su interés en ámbito de la lexicografía.

\section{LOS GENTILICIOS: CONCEPTO, FORMACIÓN, ASPECTOS LÉXICO SEMÁNTICOS Y LEXICOGRÁFICOS}

Como señala Morera (2011: 95 y ss.), el español puede expresar gramatical o léxicamente «la procedencia u origen espacial de las personas, los animales o las cosas». La relación gentilicia gramatical se materializa o bien de manera externa a través de un sintagma preposicional constituido por la preposición de y el nombre de lugar de que se trata, o bien de forma interna, mediante un sufijo que, de alguna manera, cuantifica la materia semántica de la base, que suele ser un topónimo ${ }^{1}$. Los sufijos empleados para realizar esta función son limitados. Morera (ibidem) recoge un catálogo de formas (-aco, -ano, -ata, -eco, -enco, -ense, -eño, -ero, -és, -esco, -í, -ico, -iego, -ino, -ita, ón, ota y -uno) y el hecho de que aparezca una u otra se debe a variadas razones de índole histórica, fónica o semántica, etc. García Padrón (2012a) analiza los procedimientos de carácter fónico que se hallan detrás la formación de gentilicios. La autora señala que, con carácter general, existen dos fundamentales: a) la ampliación, alargamiento o crecimiento silábico de la base y b) su acortamiento o decrecimiento silábico, siendo irrelevante que el topónimo que sirve de base sea mono o poliléxico ${ }^{2}$. García Padrón (ibid.) también habla de un tercer grupo de gentilicios que no se han creado ni por alargamiento ni por acortamiento sino por otros fenómenos (de orden fónico, gramatical o léxico), como las mutaciones vocálicas para evitar el mismo timbre en toda la secuencia fónica (mogareño < Moguer), la alternancia consonántica (de -l-/-n-; p.e., en malizalita < Manizales) y la metátesis (dianense < Denia). También, aunque no es lo más frecuente, se pueden crear formas gentilicias sobre la lexicalización de las siglas de determinados topónimos (usamericano, defecal, etc.). Otra cuestión interesante que me gustaría recoger en este punto por su importancia para nuestro estudio posterior sobre el DPD es la de los alogentilicios, en palabras de García Padrón (2012b: 147) «especie de sinónimos, de variantes libres que el hablante tiene a su disposición, de manera que no habría diferencia en su alternancia comunicativa». En su mayoría, reflejarían pequeñas modificaciones de expresión sufridas en la base con el paso del tiempo y o motivadas por fenómenos fónicos o gráficos (jerosolimitano/hierosolimitano).

Por su parte, la relación gentilicia se puede expresar también léxicamente mediante el uso de un lexema nominal o adjetival que expresa la noción de origen pero sin aludir explícitamente al lugar de que se trata. Normalmente, a estos se les denomina paragentilicios (pseudogentilicios, gentilicios informales o burlescos, etc.), puesto que llevan aparejados una serie de valoraciones - sobre todo peyorativas - realizadas por el otro que no es de ese lugar (yanqui, por ejemplo, para el individuo procedente de EE.UU.)

\footnotetext{
${ }^{1}$ Aunque no siempre es el topónimo la base a partir de la que se crea el gentilicio, sino que el gentilicio el que sirve de base para el topónimo. Es lo que Morera (2012a) llama gentilicios primarios.

${ }^{2}$ Resulta muy interesante el caso de los acortamientos puros, esto es, cuando es la base sin sufijo la que se acorta. Estos gentilicios tendrían un valor no formal y «cohabitarían» con sus variantes neutras (japo, nica o pana para japonés, nicaragüense y panameño respectivamente).
} 
Los gentilicios gramaticales generados a partir de la adición de un sufijo — pudiendo intervenir otros hechos en la base del derivado, como se puede ver supra - pueden ser objeto de ampliación designativa, como muy bien ha indicado Morera $(2012 b)^{3}$ y de adquirir en esas ampliaciones connotaciones diversas, sobre todo, negativas, como, gran parte de las veces, los gentilicios formados a partir de lexemas que nada tienen que ver con el lugar de procedencia. Precisamente, por esta heterogeneidad a la hora de expresar la procedencia espacial, se han alzado voces contrarias a la inclusión de los gentilicios en las obras lexicográficas. No obstante, particularmente hago mías las palabras de García Padrón y Morera (2014) en sus consideraciones acerca de los motivos por los que deben incluirse los gentilicios en las obras lexicográficas ( $c f$. ., en este mismo sentido, Herrera Santana).

\section{EL TRATAMIENTO DE LOS GENTILICIOS EN EL DPD}

\subsection{Preliminar}

Dada la naturaleza del DPD, es decir, que se trata de un diccionario de dudas, elaborado, fundamentalmente, a partir de las preguntas efectuadas a las Academias de la lengua española, no recoge ni mucho menos, todos los gentilicios que podemos encontrar en el Diccionario académico. En el DPD los adjetivos gentilicios se registran en dos lugares diferentes: a) en un apéndice al final de la obra que lleva por título «Países y capitales, con sus gentilicios»; b) en el cuerpo del diccionario, donde, por un lado, se ofrece información de distinto tipo (gráfica, fónica, morfológica, normativa, etc.) en relación con algunos topónimos marcados en el apéndice, donde también se incluyen datos sobre los gentilicios que se han asociado a dichos topónimos y, por otro, gentilicios asociados a topónimos diferentes de los existentes en el apéndice.

\subsection{El apéndice}

\subsubsection{Generalidades}

En primer lugar, me referiré al apéndice ${ }^{4}$. Se trata de un catálogo, donde se incluyen por orden puramente alfabético topónimos de capitales y de países. En este punto, considero que no ha sido esta la manera más afortunada de organizar formalmente esta sección del diccionario. Hubiera sido preferible, como se ha hecho en otras secciones del DPD (la de los pronombres personales tónicos y átonos, por ejemplo), ofrecer la información en forma tabular, separando denominaciones de países y capitales. De esta forma, se hubiera podido relacionar de forma clara e inequívoca capital(es) y país(es) y se hubiera facilitado la consulta. Según las «advertencias» preliminares que hacen los

\footnotetext{
${ }^{3}$ La ampliación designativa puede darse por metonimia, atendiendo a dos variantes (ampliación contigua y discontinua) y por desplazamiento metafórico, por comparación del nuevo grupo que se designa con el grupo primitivamente designado (Morera 2012b: 189-190).

${ }^{4}$ Para efectuar el análisis de los gentilicios recogidos en el DPD me he servido de la versión en línea de la obra dada su mayor facilidad de manejo, (http://www.rae.es/diccionario-panhispanico-dedudas/apendices/paises-y-capitales-con-sus-gentilicios).
} 
autores del diccionario, este apéndice contiene las denominaciones de los países reconocidos por la ONU y sus capitales, además de los gentilicios «recomendados», cuando existen. Se nos avanza también que se registran algunos nombres de estados y/o capitales anteriores a las modificaciones que han dado lugar a una nueva denominación vigente en el momento de publicación del diccionario. Además, se explicita que algunos topónimos vendrán acompañados del artículo entre paréntesis, cuando el uso del mismo en español se encuentre asociado opcional u obligatoriamente a dicho topónimo. En la última advertencia se indica que los topónimos marcados con asterisco ${ }^{5}$ presentan una entrada más amplia en el cuerpo del diccionario. En cuanto a estas aseveraciones, me gustaría precisar y comentar críticamente lo siguiente:

1. En esta lista alfabética, a pesar de lo que se dice en las «advertencias», no solo podemos consultar países reconocidos por la ONU sino otros que no tienen dicho estatuto internacional. Son los casos (cf. García Padrón 2012b) de Puerto Rico, que, como se indica en la propia obra, es un Estado libre asociado a los EE.UU; Ciudad del Vaticano, que tiene el estatus de estado no miembro con invitación permanente para participar como observador en los períodos de sesiones y en los trabajos de la Asamblea General y que mantiene misión permanente de observación en la Sede de las Naciones Unidas (cf. García Padrón 2012b). Lo mismo puede decirse de Jerusalén, que se incluye como capital no reconocida por la ONU de Israel. Curiosamente, no se recoge la capital reconocida por la ONU, Tel Aviv. Podemos ver, sin embargo, que el apéndice alberga las denominaciones de las tres ciudades que forman la capitalidad de Sudáfrica (la capital administrativa, Ciudad del Cabo; la capital judicial, Bloemfontein y la capital legislativa, Pretoria), las dos de Suazilandia (la capital administrativa, Mbabane y la capital legislativa, Lobamba) y las «dos» de Bolivia (la capital administrativa, La Paz y la constitucional Sucre).

Por lo demás, resulta llamativa la falta de coherencia del DPD a la hora de establecer las denominaciones de países, puesto que, en algunos casos, hace uso de los nombres oficiales y en otros de los que tradicionalmente se han empleado y siguen en uso en la actualidad. Los ejemplos más flagrantes son los registros de Reino Unido de Gran Bretaña e Irlanda del Norte, cuando, para referirse a esa entidad, se ha solido emplear únicamente la forma acortada Reino Unido (en la entrada en el cuerpo del diccionario s. v. Reino Unido); y de Rusia, oficialmente Federación de Rusia o Federación Rusa ${ }^{6}$.

2. En la nómina de topónimos, se constata, en efecto, la presencia de las denominaciones de antiguas capitales de países (Abiyán, capital de Costa de Marfil hasta 1983) y de nombres de países que, en la actualidad, han dejado de ser reconocidos internacionalmente, es decir, lo que podrían considerarse, siquiera en algunos casos, variantes

\footnotetext{
${ }^{5}$ Aunque se aclara cuál es la función del asterisco en las «advertencias», lo cierto es que resulta, cuando menos, poco apropiado el uso de este signo dado que el mismo signo se emplea en el cuerpo del diccionario para indicar construcciones agramaticales.

${ }^{6}$ La incoherencia queda aún más patente en este último caso, cuando el lector se dirige a algunos artículos del cuerpo del DPD, los que registran los topónimos de las antiguas repúblicas soviéticas, y encuentra textos como los siguientes: «Tartaristán. Forma recomendada en español como nombre de la república de la Federación Rusa cuya capital es Kazán [...]»(DPD, s. v. Tartaristán); «Kalmukia. Forma recomendada en español para el nombre de esta república de la Federación Rusa [...]» (DPD, s. v. Kalmukia; la cursiva es mía).
} 
diacrónicas. Me refiero a Alto Volta (actual Burkina Faso), Ceilán (actual Sri Lanka), Dahomey (actual Benín), Rodesia (actuales Zimbabue y Zambia) y Zaire (actual República Democrática del Congo). Se me esconde la razón o razones de los autores del DPD para registrar estos topónimos si no están actualmente vigentes. La única explicación que se ofrece es que el cambio de denominación es relativamente reciente. Por esta misma regla, podría haberse incluido la URSS, por ejemplo, y no se ha hecho. Sin embargo, la nueva denominación oficial de Birmania, Myanmar, no se recoge en esta lista, a pesar de que en el artículo que tiene el topónimo en el cuerpo del diccionario se reconoce que, precisamente, Myanmar es el nombre actual y oficial del país (DPD, s. v. Birmania) ${ }^{7}$.

Hay que tener en cuenta que algunos cambios políticos posteriores a la publicación del diccionario han originado nuevas modificaciones en algunas denominaciones de países. Así, tenemos en la lista del DPD Serbia y Montenegro, aludiendo a una entidad que se convirtió más tarde en dos estados diferentes con reconocimiento internacional: Serbia y Montenegro. De la misma forma, en la obra, se registra la forma Sudán; sin embargo, el sujeto de Derecho Internacional al que se alude con dicho topónimo sufrió la desmembración de una parte de su territorio en 2011 que adquirió el estatus de estado reconocido por la ONU el 21 de julio de 2011 con el nombre de Sudán del Sur.

3. En el catálogo se reúnen, asimismo, variantes léxicas y gráficas de un topónimo en entradas separadas con remisiones: Paises Bajos/Holanda; Antigua República Yugoslava de Macedonia/Macedonia, Iraq/Irak; al mismo tiempo, aparecen en la misma entrada variantes que obedecen a razones dialectales separadas mediante la conjunción disyuntiva o Arabia Saudí o Arabia Saudita, Nueva Zelanda o Zelandia y Rumanía o Rumania. La misma técnica se emplea a la hora de ofrecer variantes gentilicias (p.e. angoleño,-ña o angolano,-na saudí o saudita, brasileño o brasilero etc.).

4. En una de las advertencias de los autores del DPD, se señala, como ya hemos adelantado, que algunos topónimos vienen acompañados del artículo, que puede ser de uso obligatorio u optativo, según los casos. Hubiera sido deseable, sobre todo en atención al lector no demasiado ducho en cuestiones lingüísticas, poner alguna marca que indicara, en qué casos el empleo del topónimo con artículo es obligatorio y en cuáles opcional. En la tabla siguiente se registran las denominaciones que en el DPD aparecen con artículo ${ }^{8}$.

\begin{tabular}{|l|l|}
\hline Argentina (la) & Japón (el) \\
\hline Bahamas (las) & Maldivas (las) \\
\hline Camerún (el) & Países Bajos (los) \\
\hline Canadá (el) & Pakistán (el) \\
\hline
\end{tabular}

${ }^{7}$ Se toma el uso mayoritario como parámatro para recomendar el exónimo Birmania. Sin embargo, este uso mayoritario se constata efectivamente hasta los años 2000, dado que, a partir de entonces, el uso de Myanmar corre paralelo al de Birmania (cf. CREA y CORPES).

${ }^{8}$ Curiosamente, no se incluye el artículo en la entrada de Vietnam, pero en el artículo correspondiente del diccionario indica que «[1]a grafía asentada en el uso español del nombre de este país de Asia es Vietnam. Es opcional su uso con artículo, aunque en la actualidad se suele prescindir de él» (DPD, s. v. Vietnam). 


\begin{tabular}{|l|l|}
\hline Chad (el) & Paraguay (el) \\
\hline China (la) & Perú (el) \\
\hline Comoras (las) & República Centroafricana (la) \\
\hline Congo (el) & República Checa (la) \\
\hline Ecuador (el) & República Democrática del Congo (la) \\
\hline Emiratos Árabes Unidos (los) & República Dominicana (la) \\
\hline Estados Unidos de América (los) & Senegal (el) \\
\hline Gabón (el) & Seychelles (las) \\
\hline Guinea (la) & Sudán (el) \\
\hline Guinea Ecuatorial (la) & Togo (el) \\
\hline India (la) & Uruguay (el) \\
\hline Islas Marshall (las) & Zaire (el) \\
\hline Islas Salomón (las) & \\
\hline
\end{tabular}

Tabla 1. Lista alfabética con las denominaciones de países acompañados de artículo obligatorio u optativo en el apéndice de «Países y capitales, con sus gentilicios» del DPD

\subsubsection{Estadísticas}

1. En total se recogen 399 entradas si no se toman en consideración las que cuentan con remisiones a formas gráficas diferentes (Camberra/Canberra, Irak/Iraq) y $401 \mathrm{si}$ se consideran todas. Del total, 201 (o 202, por la razón esgrimida anteriormente) corresponden a topónimos de países y 198 (o 199) a denominaciones de capitales. Por motivos obvios - se trata, con ciertas salvedades que ya hemos hecho, de los países reconocidos por la ONU - la mayor parte de las formas que se recogen se refieren a topónimos vehiculados (actual y oficialmente) a través de lenguas diferentes del español (181 topónimos de países o aprox. el 45\% del total de topónimos recogidos o el $90 \%$ de los correspondientes al total de países; 177 topónimos de capitales, en torno a un $45 \%$ del total y a un $90 \%$ de las capitales). La forma en que se han fijado los exónimos para el español por el DPD no ha estado exenta de polémica. Así, según la opinión de Bezos (2012), los autores del DPD se exceden en sus atribuciones en el caso de la toponimia $-\mathrm{y}$, por ende, en los gentilicios, según mi opinión - al querer regular la escritura de lenguas extranjeras en el caso de topónimos que no son tradicionales, es decir, aquellos que no «han evolucionado en nuestra lengua de forma independiente de la original para adaptarse a su fonética y ortografía». El parecer del autor se halla, en este sentido, en consonancia con la Conferencia de las Naciones Unidas sobre la Normalización de Nombres Geográficos (United Nations Conference on the Standardization of Geographical Names - UNCSGN), que recomienda, con el fin de crear una nomenclatura geográfica uniforme en todo el mundo, que no se creen nuevos exónimos y se emplee el topónimo oficial ${ }^{9}$. Otros autores, como Martínez de Sousa (2007: 371), son contrarios a esta tendencia y consideran que el empleo y la creación de exónimos

\footnotetext{
${ }^{9}$ Como señala García Sánchez (2009: 4), la pretensión de que se reconociera un endónimo oficial en el ámbito internacional fue llevada a sus últimas consecuencias por las autoridades gubernamentales de Costa de Marfil que lograron, incluso, que la denominación en francés Côte d'Ivoire fuera recogida por la ONU en su catálogo de miembros en todas las lenguas.
} 
debe ser obligatoria, por motivos de coherencia y para evitar ambigüedades innecesarias, por lo menos, en los ámbitos no oficiales.

2. De la totalidad de entradas del apéndice, se ofrece información sobre gentilicios en 239 entradas (aprox. 59.9\%): 193 en las entradas de topónimos de países (aprox. $48.4 \%$ ) y 46 (aprox. $11.5 \%$ ) y aprox. un $96 \%$ del total de topónimos de países y un $23 \%$ de la totalidad de nombres de capitales. Las entradas con más de una forma gentilicia recomendada ascienden a 16 , esto es, en torno a un $6.7 \%$ del total, lo cual apunta indiciariamente a la intención prescriptivista de las Academias, pero también habría que decir que tras la inclusión de dos o más alogentilicios ( $c f$. García Padrón 2012b) se muestra la idea de, fundamentalmente, reflejar y acoger la variación gráfica, morfológica y léxica por motivos dialectales, diacrónicos, etc.

\begin{tabular}{|c|c|c|c|}
\hline \multicolumn{4}{|c|}{ TOPÓNIMOS DEL DPD RELACIONADOS CON MÁS DE UNA FORMA GENTILICIA RECOMENDADA } \\
\hline PAÍSES & $\begin{array}{l}\text { FORMAS GENTILICIAS RECO- } \\
\text { MENDADAS }\end{array}$ & CAPITALES & $\begin{array}{l}\text { FORMAS GENTILICIAS } \\
\text { RECOMENDADAS }\end{array}$ \\
\hline Angola & $\begin{array}{l}\text { angoleño,-ña } o \text { angolano,-na } \\
\text { [Cuba] }\end{array}$ & Asunción & $\begin{array}{l}\text { asunceno,-na } o \text { asunceño, } \\
\text {-ña }\end{array}$ \\
\hline $\begin{array}{l}\text { Arabia Saudí } o \\
\text { Arabia Saudita }\end{array}$ & saudí $o$ saudita & $\begin{array}{l}\text { Canberra / } \\
\text { Camberra }\end{array}$ & $\begin{array}{l}\text { canberrano,-na } o \text { cambe- } \\
\text { rrano,-na }\end{array}$ \\
\hline Austria & austriaco,-ca $o$ austríaco,-ca & París & parisino,-na $o$ parisiense \\
\hline $\begin{array}{l}\text { Bosnia- } \\
\text { Herzegovina }\end{array}$ & $\begin{array}{l}\text { bosnio,-nia } o \text { bosnioherzego- } \\
\text { vino,-na }\end{array}$ & & \\
\hline Brasil & $\begin{array}{l}\text { brasileño,-ña } o \text { brasilero,-a } \\
\text { [Am.] }\end{array}$ & & \\
\hline Jamaica & $\begin{array}{l}\text { jamaicano,-na } o \text { jamaiquino,- } \\
\text { na [Am.] }\end{array}$ & & \\
\hline Kenia & keniano,-na $o$ keniata & & \\
\hline Kirguistán & kirguís $o$ kirguiso,-sa & & \\
\hline Mali $o$ Malí & maliense $o$ malí & & \\
\hline Nepal & nepalés,-sa $o$ nepalí & & \\
\hline Qatar & catarí $o$ qatarí & & \\
\hline Sri Lanka & $\begin{array}{l}\text { ceilanés, -sa, ceilandés,-sa, } o \\
\text { esrilanqués, -sa }\end{array}$ & & \\
\hline Turkmenistán & turcomano,-na $o$ turkmeno,-na & & \\
\hline
\end{tabular}

3. 72 topónimos de países aparecen marcados con asterisco (aprox. 18\% del total y aprox. $38 \%$ del total de países) frente a 50 de ciudades capitalinas (aprox. 12.5 del total y aprox. $25 \%$ del total de capitales), es decir, un total de 122 denominaciones tienen entrada separada en el cuerpo del diccionario ( $30.5 \%$ del total). Salvo en dos supuestos (Rumanía o Rumania y Palau), en todas las entradas en el cuerpo del diccionario relacionadas con topónimos marcados del apéndice se ofrecen comentarios de mayor o menor amplitud sobre los gentilicios recomendados y otras formas verificables. En este punto, no puedo menos que indicar que se constata cierta incoherencia $-\mathrm{o}$, sencillamente, despiste de los redactores - en el empleo de este signo, produciéndose situaciones como las que describo a continuación: a) algunos topónimos no poseen asterisco y, sin embargo, cuentan con un artículo propio en el diccionario. Es el caso, p.e., de 
Camboya, Vietnam o Yibuti; b) algunos topónimos con formas gentilicias recomendadas no se hallan marcados, pero los gentilicios disponen de un artículo propio ${ }^{10}$ en el diccionario. Son los supuestos de angoleño-ña, austriaco,-ca o austríaco,-ca, danés,-sa, dominicano,-na, dominiqués,-sa, etíope, israelí, puertorriqueño,-ña, santiaguino,-na, ucraniano,-na. Hubiera sido deseable, para facilitar la consulta, que se hubieran marcado también los gentilicios.

4. El criterio de la «recomendación» resulta equívoco en el apéndice, puesto que, en algunas entradas del mismo, no se consigna forma gentilicia recomendada alguna; sin embargo, si el usuario se dirige al artículo dentro del diccionario sobre el topónimo correspondiente, aparece una forma gentilicia. Esto ocurre, p.e., en el topónimo Tokio, marcado con asterisco, pero sin gentilicio recomendado. En el artículo del diccionario, aparece, no obstante, el siguiente texto: «Tokio. [...] Como gentilicio se emplea la forma tokio$t a$, válida para ambos géneros: «Oka menciona también la baja calidad de vida de los tokiotas debido a la alta densidad de la población» (DYucatán [Méx.] 15.12.97» (DPD, s. v. Tokio). ¿Como se ha de interpretar este texto? ¿Que este gentilicio se usa pero no es recomendable? Con casi toda seguridad ha debido de ser un descuido de los redactores, que es lo mismo que ha ocurrido con el topónimo Jerusalén, sin gentilicio recomendado en el apéndice pero con un artículo en el diccionario, donde de forma explícita se recomienda un gentilicio determinado: «Jerusalén. El gentilicio recomendado es jerosolimitano [...]». (DPD, s. v. Jerusalén). El silencio en torno a la capital de México, México $D . F$. , es atronador. Ni hay asterisco en su entrada ni gentilicio recomendado. ¿Qué ha ocurrido con el defeño,-ña del DRAE (s. v. defeño)?

Por lo demás, resulta poco coherente el hecho de que se registren en el apéndice dos formas como variantes gentilicias (gráficas o morfológicas, no motivadas dialectalmente) recomendadas - lo cual hace creer al usuario que ambas están en pie de igualdad—, para acto seguido, en el artículo del diccionario destacar el uso minoritario o menos privilegiado de una de ellas. Esto es lo que sucede, p. e., con keniano,-na/keniata, maliense/mali y con bosnio,-nia/bosnioherzegovino,-na, en los que se favorece el empleo de la primera forma por tener un uso mayoritario y tradicional (keniano,-na frente a keniata; maliense frente $a$ mali) o se indica la poca frecuencia de uso de la segunda bosnioherzegovino,-na frente a bosnio,-nia. Por el contrario, para otros topónimos solo se recomienda un gentilicio en el apéndice, pero en el cuerpo del diccionario se reconocen como válidas otras formas. Me refiero a danés,-sa, donde se indica que dinamarqués,-sa es igualmente válido como gentilicio. Ante tal situación, me pregunto por qué se incluyen para algunos topónimos dos formas gentilicias como recomendadas si luego parece que las mismas no se emplean o se pueden emplear indistintamente y se establece en los artículos correspondientes una discusión acerca de cuál es más recomendable? O, a contrario, ¿por qué

\footnotetext{
${ }^{10}$ En este caso no me refiero a gentilicios con entrada en el cuerpo del diccionario, pero sin artículo propio, sino solo con una mera remisión al topónimo correspondiente. Ejemplos de ello serían angolano,-na, que remite a angoleño,-ña y todos los que aparecen en la Tabla 3 de este trabajo, a excepción de asunceno,-na, asunceño,-ña y parisino,-na, parisiense. Se me escapa, nuevamente, en este supuesto, la falta de sistematicidad de los redactores de la obra.
} 
no se incluyen en el apéndice como variantes algunas que luego se tratan en el cuerpo del diccionario, dándoles la misma validez que a la recomendada?

Este criterio de las formas gentilicas recomendadas da lugar, igualmente, de manera indirecta, a soluciones que rozan lo demencial, sobre todo, en lo referente a topónimos que han cambiado y que conviven con los antiguos. Para Zaire (actual República Democrática del Congo) se recomienda en el apéndice un gentilicio zaireño,-ña, mientras que, para Alto Volta (sin asterisco) no recomienda ninguno, sino que se remite indirectamente a Burkina Faso. En esta entrada del apéndice, marcada con asterisco, tampoco se recomienda forma alguna; sin embargo, en el cuerpo del diccionario se pueden encontrar dos entradas, una para voltense y otra para burkinés. Ambas remiten a la de Burkina Faso, donde, en su artículo, se indica que su gentilicio es burkinés y que voltense no se aconseja por ser derivado de la antigua denominación. Pero, ¿zaireño,-ña no es también un derivado de un topónimo que ha cambiado? ¿Por qué se recomienda entonces? Se recomiendan también las formas ceilanés,-sa, ceilandés,-sa y esrilanqués,-sa, a pesar de que Ceilán es una denominación que ha sido modificada por Sri Lanka, con entrada separada en el diccionario. De Rodesia, que posee artículo propio en el cuerpo del diccionario, no se indica nada sobre el gentilicio, ni siquiera se da cuenta de la existencia de la forma rodesiano,-na que se constata en textos de prensa españoles de los años 70 y 80 del siglo $\mathrm{Xx}^{11}$, en un diario de tirada nacional, siquiera para decir que se desaconseja su uso $\mathrm{y}$ justificarlo. Lo mismo ocurre con Dahomey, donde se remite también indirectamente a Benín, topónimo para el que se registra beninés,-sa como forma gentilicia recomendada obviando la existencia de dahomeyano,-na ${ }^{12}$.

5. En las «advertencias» previas se establece que se recogerán las formas gentilicias recomendadas cuando estas existan. Este criterio de la «existencia» resulta inquietante, pues ya se ha podido ver en los ejemplos anteriores que formas como rodesiano,-na o dahomeyano,-na son verificables. Creo que debió de haberse explicitado qué valor tiene realmente la expresión «cuando existen» que leemos en las advertencias. ¿Se refiere a cuando estas formas se registran en el DRAE, cuando se encuentran en las bases de datos académicas? Y en este último supuesto, ¿a partir de cuándo o en qué circunstancias se puede considerar que los testimonio son suficientes y necesarios para que esa forma se consolide como «existente»? Por lo demás, hubiera sido una oportunidad de oro para ofrecer una solución a la supuesta «inexistencia» proponiendo nuevos gentilicios. Para finalizar este apartado, me resumiré en una tabla los datos estadísticos ofrecidos en los apartados 1, 2 y 3 de este subepígrafe.

\footnotetext{
${ }^{11}$ En el CREA podemos encontrar 26 ocurrencias de la forma sing. masc. rodesiano, 6 de la pl. masc., 16 de la sing. fem. y 13 de la pl. fem.

${ }^{12}$ En el CREA se registran 11 ocurrencias de la forma sing. masc. dahomeyano, 8 de la pl. masc., 15 de la sing. fem. y 2 de la pl. fem.
} 


\begin{tabular}{|l|c|c|c|}
\hline & $\begin{array}{l}\text { ENTRADAS } \\
\text { TOTALES }\end{array}$ & $\begin{array}{l}\text { ENTRADAS DE DE- } \\
\text { NOMINACIONES } \\
\text { PAÍSES }\end{array}$ & $\begin{array}{l}\text { ENTRADAS DE DE- } \\
\text { NOMINACIONES DE } \\
\text { CAPITALES }\end{array}$ \\
\hline $\mathrm{N}^{\circ}$ de entradas & $399 / 401$ & $201 / 202$ & $198 / 199$ \\
\hline $\begin{array}{l}\mathrm{N}^{\circ} \text { de entradas de topónimos } \\
\text { de ámbito no hispánico }\end{array}$ & 358 & 181 & 177 \\
\hline $\begin{array}{l}\mathrm{N}^{\circ} \text { de entradas de topóni- } \\
\text { mos de ámbito hispánico }\end{array}$ & 41 & 20 & 21 \\
\hline $\begin{array}{l}\mathrm{N}^{\circ} \text { de entradas con informa- } \\
\text { ción gentilicia (gentilicios } \\
\text { recomendados) }\end{array}$ & 239 & 193 & 3 \\
\hline $\begin{array}{l}\mathrm{N}^{\circ} \text { de entradas con más de } \\
\text { una forma gentilicia reco- } \\
\text { mendada }\end{array}$ & 16 & 13 & \\
\hline $\begin{array}{l}\mathrm{N}^{\circ} \text { de entradas marcadas } \\
\text { con asterisco }\end{array}$ & 122 & 72 & 50 \\
\hline
\end{tabular}

Tabla 3. Datos estadísticos correspondientes al apéndice de «Países y capitales, con sus gentilicios» del DPD

\subsection{Los gentilicios en el cuerpo del diccionario}

\subsubsection{Generalidades}

En el cuerpo del diccionario se registran también gentilicios asociados a topónimos diferentes de los existentes en el apéndice. Estas formas gentilicias y toponímicas son muy variadas, una buena parte extranjeras, referidas a zonas geográficas menores y mayores que países, incluso áreas que, en la actualidad, no se reconocen como tales, pero sí tuvieron gran importancia en el pasado (Ándalus, p.e.).

\subsubsection{Estadísticas}

En total se contabilizan 121 entradas en bruto, es decir, tomando en consideración las que contienen variantes gráficas, fónico-gráficas o morfológicas de un mismo gentilicio que aparecen en la misma entrada, p.e. alaskeño,-ña, alasqueño,-ña; sefaradí, sefaradita; o, por el contrario, cuentan con entradas diferentes, p.e. yugoeslavo,-a/yugoslavo- $a$. He incluido, además, entradas con formas consideradas incorrectas o desaconsejables, como celandés,-sa, tajik, estadinense o usamericano,-na. En cuanto a este punto, no entiendo por qué se recogen formas consideradas incorrectas en entradas separadas, cuando lo lógico habría sido explicarlas en el artículo correspondiente y a colación de las formas estimadas correctas o aconsejables. Tampoco entiendo la disparidad de criterios a la hora de incluir diferentes formas en una entrada. Así, por ejemplo, checoeslovaco -ca, Checoeslovaquia, checoslovaco -ca. $\rightarrow$ Checoslovaquia, pero Yugoeslavia, yugoeslavo -va $\rightarrow$ Yugoslavia y yugoslavo -va $\rightarrow$ Yugoslavia. De estas entradas, 93, es decir, casi un $77 \%$, recogen gentilicios relacionados con topónimos vehiculados actualmente a través de lenguas diferentes al español, mientras que las entradas con formas gentilicias asociadas a topónimos hispánicos son 28 , aprox. un $23 \%$. 


\subsection{Los gentilicios. Norma y orientación en el DPD}

Parece que los autores del DPD han seguido dos criterios, fundamentalmente, a la hora recomendar o establecer la o las formas gentilicias para un topónimo determinado: 1) el uso (culto) mayoritario y su adecuación al sistema lingüístico español (fónicográfico, morfológico, léxico, etc.) frente — sobre todo, aunque no solo- a otros sistemas «distorsionadores»y generadores de interferencias lingüísticas (entiéndase lenguas coloniales o mediadoras como el inglés o el francés). Pero, seguidamente, veremos que estos dos criterios no se siguen de manera armónica y, tras un análisis detallado de los artículos lexicográficos en el cuerpo del diccionario, se llega a la conclusión de que se ha actuado, en muchos casos, asistemáticamente: como si a cada caso se le hubiera aplicado una solución particular. Esa misma asistematicidad se constata igualmente en la expresión que, si bien es terminante unas veces, marcando claramente preceptos, otras es ambigua y el usuario: si se está describiendo, si se están rechazando u ofreciendo posibilidades igualmente válidas o inválidas para todos los contextos, a pesar que algunas sean de uso mayoritario o minoritario, etc. El problema es que la obra parece siempre situada entre el uso real y el precepto. Prueba de esto último, es el empleo expresiones del tipo que se señalan en el cuadro que sigue a continuación:

\begin{tabular}{|c|c|}
\hline $\begin{array}{l}\text { EXPRESIONES } \\
\text { PRESCRIPTIVAS }\end{array}$ & EJEMPLOS TEXTUALES \\
\hline $\begin{array}{l}\text { (No) debe usarse } \\
\text { en español } \\
\text { (No) debe em- } \\
\text { plearse }\end{array}$ & $\begin{array}{l}\text { «No debe usarse en español la grafía inglesa Buryatia. El gentilicio } \\
\text { recomendado es buriato» (DPD, s. v. Buriatia) } \\
\text { «No debe usarse como gentilicio en español la forma latvio» (DPD, s. v. } \\
\text { Lituania) } \\
\text { «No deben usarse en español ni la forma francesa Strasbourg ni la } \\
\text { alemana Strassburg; tampoco la híbrida Strasburgo. El gentilicio es } \\
\text { estrasburgués» (DPD, s. v. Estrasburgo) } \\
\text { «[...] en textos escritos en castellano debe emplearse el topónimo caste- } \\
\text { llano. El gentilicio es coruñés» (DPD, s. v. La Coruña) } \\
\text { «El gentilicio es bielorruso (y no belaruso ni belarruso)» (DPD, s. v. } \\
\text { Bielorrusia) }\end{array}$ \\
\hline $\begin{array}{l}\text { Como gentili- } \\
\text { cio }(s) \text { son válidos } \\
\mathrm{x} e \mathrm{y}\end{array}$ & $\begin{array}{l}\text { «Como gentilicios son válidos daguestano y daguestaní [...]» (DPD, } s \text {. } \\
v \text {. Daguestán) }\end{array}$ \\
\hline $\begin{array}{l}\text { El gentilicio es } \mathrm{x} \\
\text { (y) no y (con } \\
\text { ciertas variacio- } \\
\text { nes) }\end{array}$ & $\begin{array}{l}\text { «El gentilicio es floridano (no floridiano).» (DPD, s. } v \text {. Florida) } \\
\text { «Su gentilicio es afgano; la forma afgani es únicamente el nombre de la } \\
\text { moneda oficial, no el gentilicio» (DPD, s. } v \text {. Afganistán) }\end{array}$ \\
\hline $\begin{array}{l}\text { Es impropio usar } \\
\mathrm{x} \text { como gentilicio } \\
\text { de y }\end{array}$ & $\begin{array}{l}\text { «Es impropio usar carioca como gentilicio de Brasil. Es impropio su } \\
\text { empleo con el sentido más general de 'brasileño', error frecuente en el } \\
\text { lenguaje deportivo: }{ }^{\otimes} \text { "Brasil tuvo ayer sus primeras dificultades [...]. } \\
\text { La selección carioca logró remontar un partido que perdia por dos } \\
\text { goles en el descanso» (País [Esp.] 18.6.97).»(DPD, s. v. Brasil) }\end{array}$ \\
\hline $\begin{array}{l}\text { No se admite(n) } \\
\text { el(los)/como } \\
\text { gentilicio(s) }\end{array}$ & $\begin{array}{l}\text { «No se admiten como gentilicios ni burkinabé, calco rechazable del } \\
\text { francés, ni burkinabés, formado a partir del anterior» (DPD, s. v. Bur- } \\
\text { kina Faso) } \\
\text { «No se admite el gentilicio }{ }^{\otimes} \text { mayamero, derivado del topónimo angli- } \\
\text { cado antes censurado» (DPD, s. v. Miami) }\end{array}$ \\
\hline $\begin{array}{l}\text { No se considera } \\
\text { aceptable el uso } \\
\text { del gentilicio } \mathrm{x}\end{array}$ & $\begin{array}{l}\text { «No se considera aceptable el uso del gentilicio inglés tajik ni el de su } \\
\text { adaptación tayik» (DPD, s. v. Tayikistán) }\end{array}$ \\
\hline Debe evitarse & $\begin{array}{l}\text { «Debe evitarse el empleo de la voz usamericano, por estar formada } \\
\text { sobre la sigla inglesa» (DPD, s. v. Estados Unidos) }\end{array}$ \\
\hline
\end{tabular}




\begin{tabular}{|c|c|}
\hline $\begin{array}{l}\text { EXPRESIONES } \\
\text { ORIENTADORAS , } \\
\text { AMBIGUAS }\end{array}$ & EJEMPLOS TEXTUALES \\
\hline $\begin{array}{l}\text { El gentilicio (re- } \\
\text { comendado) es }\end{array}$ & $\begin{array}{l}\text { «Su gentilicio es azerbaiyano: "Este puente fue asaltado el día } 22 \text { por } \\
\text { una multitud exaltada de azerbaiyanos» (País [Esp.] 1.12.88). [...] } 2 . \\
\text { También se utiliza como gentilicio la forma azerí» (DPD, s. v. Azerbai- } \\
\text { yán) }\end{array}$ \\
\hline $\begin{array}{l}\text { Como gentilicio se } \\
\text { recomienda }\end{array}$ & $\begin{array}{l}\text { «Como gentilicio se recomienda la forma sancristobaleño» (DPD, s. } \\
\text { v. San Cristóbal y Nieves) } \\
\text { «Como gentilicio se recomienda el tradicional kirguís, válido para } \\
\text { ambos géneros» (DPD, s. v. Kirguistán) }\end{array}$ \\
\hline $\begin{array}{l}\text { Ser /Resultar pre- } \\
\text { ferible }(s)\end{array}$ & $\begin{array}{l}\text { «[..] resultan preferibles, como gentilicios del país, las formas ceila- } \\
\text { nés o ceilandés» (DPD, s. v. Burkina Faso) } \\
\text { «Es preferible esta forma, más frecuente en el uso, a la variante eura- } \\
\text { siático, también válida» (DPD, s. v. euroasiático,-ca) }\end{array}$ \\
\hline Se desaconseja(n) & $\begin{array}{l}\text { «[..] ambos son preferibles a los también usados kirguiz y kirguiz(i)o. } \\
\text { Se desaconsejan las variantes con qu-, por su desemejanza gráfica con } \\
\text { el topónimo» (DPD, s. v. Kirguistán) }\end{array}$ \\
\hline Se aconseja(n) & $\begin{array}{l}\text { «Como gentilicio son válidas las formas pakistaní y paquistaní, aun- } \\
\text { que por coherencia gráfica con el topónimo se aconseja usar con } \\
\text { preferencia la forma pakistani» (DPD, s. } v \text {. Pakistán) }\end{array}$ \\
\hline
\end{tabular}

Tabla 4. Expresiones prescriptivas y orientativas o ambiguas en el DPD

La falta de coherencia en el tratamiento de ciertos fenómenos gráficos, fónicográficos, morfológicos y léxico-semánticos de las formas gentilicias ha generado que, en algunos casos, se prescriba, se aconseje, recomiende etc. lo que, en otros análogos, no se admita, se desaconseje o no se recomiende. Seguidamente trataré ciertas incoherencias verificables en todos los planos lingüísticos:

\section{A. Incoherencias en el plano gráfico y fónico-gráfico}

A.1. La $<\mathrm{q}>$, la $<\mathrm{c}>$ y la $<\mathrm{k}>$ como representación gráfica de $/ \mathrm{k} /$. Este es un escollo importante en el DPD, ya en relación con los topónimos de los que suelen derivar los gentilicios. Presento algunos ejemplos:

a) Para el topónimo Iraq se admite también la forma con $<\mathrm{k}>$ (Irak) por una cuestión de tradición, dada la «anomalía» que supone la grafía $<\mathrm{q}>$ al final de palabra: sin embargo, prescribe que la forma iraki para el gentilicio no es válida, sin dar ningún tipo de explicación (DPD, $s$. v. Iraq); a pesar, incluso de que su uso se verifica en el mundo hispánico ( $c f$. CREA, $s$. v. irakí e irakies y CORPES, $s$. v. también irakí e irakies). Sin embargo, se admite e incluso se prefiere la forma gentilicia con $<\mathrm{k}>$ en los casos de pakistaní y pekinés,-sa (DPD, s. v. Pakistán y Pekín respectivamente); en este mismo sentido, resulta igualmente curiosa la consideración de incorrecta o desaconsejable la forma con $k$ del paragentilicio yanki (DPD, s. v. Estados Unidos3), por considerarse minoritaria. En el caso de Alaska (DPD, s. v. Alaska), donde se ponen en pie de igualdad tanto alasqueño,-ña como alaskeño,-ña

b) Disfuncionales resultan los supuestos de tayiko y uzbeko/uzbeco, puesto que, en el primer caso, se da como única opción gentilicia para Tayikistán, tayiko,-ka: «El gentilicio es tayiko, que también designa a los individuos de la etnia mayoritaria del país» (DPD, s. v. Tayikistán); sin embargo, para Uzbekistán (DPD, s. v.) ofrece las siguien- 
tes soluciones: «Como gentilicio son válidas las formas uzbeko y uzbeco, aunque, por coherencia gráfica con el topónimo, se aconseja usar con preferencia la primera». $\mathrm{Si}$ bien da preferencia a la variante con $k$, lo cierto es que abre la puerta al uso - por considerarse válido - de la variante con $c$, algo que no hace con tayiko, donde no se presenta discusión posible, a pesar de ser análogo a uzbek(c)o (cf. kalmuko y calmuco, $\mathrm{DPD}, s . v$. Kalmukia).

c) En el artículo dedicado a Qatar, catarí y qatarí, puede notarse también la incoherencia de admitir como gentilicios del topónimo asiático tanto la forma con $c$ como con $q$, mientras que solo se admite la forma Qatar para la denominación del país, siendo que en otras entradas podemos encontrar una correspondencia gráfica entre nombre de lugar y gentilicio. Me refiero, p.e. a serbio-bia y servio-via (a pesar de que se reconozca que la forma con - $v$ - está desusada y no se recomiende su empleo), que se hacen derivar de Serbia y Servia respectivamente (cf. también DPD, s. v. Canberra, canberrano y camberrano, que se hacen derivar de Canberra y Camberra respectivamente): «Serbia. El nombre de esta república que hoy forma, junto con la de Montenegro, un Estado europeo, se ha usado con dos grafías en español: Serbia y Servia. Esta última ha caído en desuso, por lo que no se recomienda su empleo. El gentilicio correspondiente es serbio (o servio, grafía hoy desusada)» (DPD, s. v. Serbia).

A.2. $\langle c e\rangle,\langle c i\rangle y\langle z e\rangle,\langle z i\rangle$ como representación gráfica de $\mid \theta /$. Aunque uno de los criterios determinantes del DPD con topónimos y gentilicios es su hispanización, en el sentido de su adecuación al sistema fónico y gráfico de nuestra lengua, lo cierto es que, en casos como el que sigue, se aboga por el mantenimiento de formas gráficamente alejadas de nuestra lengua: no se consideran admisibles Celanda y celandés, Nueva Celanda y neocelandés, Cimbabue y cimbabuense, Suacilandia y suaci. Me parece adecuado y coherente en el supuesto particular, pero la actitud disuasoria hacia el uso de estas grafías no se compadece con la tolerancia a la hispanización de formas también asentadas en el uso como Canberra y canberrano (cf. Camberra y camberrano, DPD, s. v. Canberra)

$$
\text { A.3. }<s>+ \text { consonante o el dígrafo }<\text { sh }>\text {. }
$$

a) Cuando un vocablo extranjero con esta secuencia en inicial de palabra se adapta al español, se le añade una $e$ inicial para apoyar su pronunciación, como todos sabemos; esta regla ha sido también habitual en la adaptación de algunos topónimos como Estocolmo (en sueco Stockholm) o Estrasburgo (en francés Strasbourg). Para este último, que incluso trata el DPD (s. $v$. Estrasburgo), los autores de la obra señalan lo siguiente: «No deben usarse en español ni la forma francesa Strasbourg ni la alemana Strassburg; tampoco la híbrida Strasburgo. El gentilicio es estrasburgués». Se constata, por tanto, la reprensión a las formas extranjeras o extranjerizantes. Sin embargo, en ningún momento, se habla de la validez de la posible adaptación de Sri Lanka, pero sí de una de sus formas gentilicias, esrilanqués (DPD, s. v. Sri Lanka), que no se valora; simplemente se describe el hecho de que esta forma está empezando a circular.

b) Tampoco resulta armónico el tratamiento del dígrafo $<$ sh $>$, que se mantiene en determinados topónimos y formas gentilicias y se elimina en otros. Así, se elimina en 
Bangladesh, a pesar de que se indica que es la forma gráfica mayoritaria, ortografiándose, por tanto, Bangladés y el gentilicio bangladesí; tampoco se adopta para Ingusetia e ingusetio (DPD, s. v. Ingusetia) ni para Chuvasia y su gentilicio chuvasio,-sia, esgrimiéndose la siguiente causa: «Se desaconseja la grafía Chuvashia, transcripción del nombre ruso que contiene el grupo $-s h$-, ajeno al sistema gráfico del español [...]. El gentilicio recomendado es chuvasio» (DPD, s. v. Chuvasia). Sin embargo, se mantiene en Islas Marshall y su gentilicio correspondiente, marshalés,-sa o en Washington y su gentilicio washingtoniano,-na (sin indicación acerca de su pronunciación, con lo que se hace un flaco favor a quienes no tengan conocimientos lingüísticos).

A.4. La grafia $<w>$. En supuestos como zimbabuense ( $<$ Zimbabue) o ruandés $(<$ Ruanda) se ha eliminado la grafía $<\mathrm{W}>$ por considerarse que esta grafía en los topónimos y gentilicios propuestos supondría una interferencia de la lengua inglesa (DPD, $s$. v. Zimbabwe y Rwanda respectivamente). Sin embargo, como señala Bezos (2012), «Zimbabwe no es una grafía inglesa, ya que el grupo $b w$ sigue las normas de las ortografías africanas en las que representa una $b$ labializada, sonido que no existe en inglés ni en español. Un caso similar es el de Rwanda, nombre autóctono de esta antigua colonia belga francófona»; por lo demás, admite la grafía $<\mathrm{W}>$ en los topónimos Malawi, aunque no en su gentilicio malaui ( $<$ Malaui) (DPD, s. v. Malaui) y también en la hispanización de Taiwán ( $>$ taiwanés).

A.5. Las grafias $\langle m>|<n>$ ante $\langle b\rangle$. El caso más flagrante de incoherencia podemos encontrarlo en el tratamiento de canberrano,-na vs. brandeburgués,sa/brandemburgués,-sa, es decir, se admite y se prefiere por estar asentada en el uso la forma gentilicia canberrano,-na $(<$ Canberra), que, sin embargo, se desaconseja en el caso de brandenburgués si extendemos la explicación que se ofrece para Brandenburgo (DPD, s. v. Brandeburgo).

Podría hablarse de otros fenómenos tratados inarmónicamente, como el papel fónico de la $<\mathrm{h}>$, que, a veces, se explica, p.e. hawaiano,-na o hongkonés, indicándose que la grafía se corresponde fónicamente con una aspiración, pero de la que, otras veces, solo recibimos silencio (ghanés,-sa $<$ Ghana, bahreiní $<$ Bahréin, p.e.) o con poco acierto, como la acentuación de topónimos de nuevo cuño.

B. Incoherencias en el plano gramatical. En este apartado solo me referiré a dos fenómenos que resultan muy llamativos y considero que deberían mejorarse en futuras ediciones del DPD. Me refiero concretamente los siguientes:

B.1 Preferencia por un tipo de sufijo sin aclarar adecuadamente. En el artículo dedicado al topónimo Yibuti (DPD, s. v.): «El gentilicio recomendado es yibutiano, aunque también se emplean las formas yibutiense y yibutí». Como he indicado, no se explica por qué se recomienda yibutiano,-na si también se usan las otras dos formas mencionadas. Lo mismo ocurre con tanzano,-na vs. tanzanio,-nia donde se prescribe, sin discusión, que el primero es la forma válida (DPD, s. v. Tanzania). En el artículo sobre cartaginés,-sa (DPD, s. v.), se señala que esta es la forma mayoritaria, que ya, de por sí, hubiera sido una explicación de por qué se recomienda frente a cartaginense, pero el problema es que se añade que, igualmente, es «preferible», sin que se explique el motivo. Lo mismo ocurre con las formas gentilicias para Quebec. Se ofrecen como alterna- 
tivas quebequés,-sa y quebequense, pero no se admiten ni quebequeño,-ña ni quebecense (DPD, s. v. Quebec), sin que se aclaren las causas.

B.2 Plurales de algunos gentilicios. En este punto hago mía la reserva de Martínez de Sousa (2005) en torno a los plurales de los gentilicios terminados en - $i$, como beirutí, magrebí, kuwaití etc., pues en ellos se admite solo la forma magrebies y no magrebis, que es plausible para palabras patrimoniales del español como alelí. El hecho de que haya una solución diferente para alelí y los gentilicios terminados en $-i$ hace que el lector se quede con la duda si va a buscar ceutí, marroquí o iraní, puesto que estas no están recogidas en el diccionario. Debió haberse incluido o hacer extensiva con alguna nota esta formación diferente del plural para los gentilicios del mismo tipo y no remitir al artículo referido al plural.

C. Incoherencias en el plano léxico-semántico. Quiero hacer mención en este apartado de dos cuestiones:

C.1 Ampliaciones y restricciones designativas. En el DPD no resulta armónica tampoco la admisión de ampliaciones y restricciones designativas de ciertos gentilicios. Por ejemplo, resultan admisibles los empleos de norteamericano,-na como variante de estadounidense (dada su frecuencia de uso) y, a pesar de reconocer que, en puridad, podría designarse a cualquier individuo proviniente de América del Norte y de yanqui, siquiera coloquialmente y con cierto matiz despectivo - aun reconociendo que la forma se empleaba originariamente como gentilicio de Nueva Inglaterra-, pero no admite carioca (DPD, $s$. v. carioca) como ampliación para designar a los que proceden de Brasil, a pesar de indicar que este uso es muy habitual en la prensa deportiva. Reconoce, igualmente, el uso como gentilicio de azerí (DPD, s. v. Azerbaiyán) sin ofrecer ninguna valoración negativa, aun cuando reseña que azeries son los individuos de la etnia mayoritaria, no todos los del país. Lo mismo cabría decir de la admisión de inglés para referirse a los individuos no solo de Inglaterra sino de todo el Reino Unido, sin mencionar si es lícito o no en textos oficiales. Se reprime, sin embargo, el uso oficial de holandés, indicándose que Holanda es solo una parte del territorio de los Países Bajos.

C. 2 Creación de gentilicios nuevos para evitar confusiones. Me refiero a los casos de andorrano,-na; argelino,-na, tunecino,-na válidos tanto para los individuos del país como de la capital o guineano,-na tanto para los de Guinea como los de Guinea-Bissáu y virginiano,-na, para los de las dos Virginias (Virginia y Virginia occidental).

\section{CONCLUSIÓN}

Tras haber efectuado un análisis más o menos detallado del tratamiento que el DPD da a las formas gentilicias, considero que lo que comentaba más arriba, esto es, que si bien, desde el punto de vista teórico, se ha dado un gran paso con esta obra, lo cierto es que la obra adolece de problemas de metodología que se traducen en errores graves deben subsanarse, como por ejemplo, la falta de precisión en la consignación de información y las deficiencias de las entradas en el apéndice, las incoherencias lingüísticas de todo tipo que podemos encontrar en los artículos interiores, la inexistencia de una marcación adecuada de los topónimos y la ambigüedad de su contenido, a pesar de que se haya intentado utilizar una expresión accesible a todo tipo de público y, sobre todo, 
una mezcla poco deseable de descripción y norma que ayuda poco a resolver las dudas que se puedan tener en el momento de utilizar una forma gentilicia. Creo que PérezSalazar Resano (2008) apuntaba una clave completamente aplicable a esta obra académica y es que se sitúa entre la orientación y el precepto y yo añado, sin demasiado éxito. Esperemos que en futuras ediciones de esta obra se solucionen estos problemas.

\section{REFERENCIAS BIBLIOGRÁFICAS}

AHUMADA, Ignacio (2012): «Ideología y corrección lingüística: los precedentes peninsulares de los diccionarios de dudas», en Félix Rodríguez González, ed., Estudios de lingüistica española, Alicante, Universidad de Alicante, pp. 55-68.

ANTOLín Y SÁEZ, Francisco (1867): Corrección de lenguaje ó sea Diccionario de disparates que contiene más de mil y cien palabras mal dichas, con su oportuna corrección, acompañadas de algunos arcaísmos y locuciones ridículas, Valladolid, Imprenta de Luis Nazario y Gaviria.

BAtres JÁUREgUI, Antonio (1892): Vicios del lenguaje y Provincialismos de Guatemala, Guatemala, Encuadernación y Tipografía Nacional.

Bezos LóPEZ, Javier (2012): «Toponimia en el Panhispánico. La falta de criterio de la RAE en el Diccionario panhispánico de dudas», en Tex y Tipografia <http://www.textipografia.com/dpdtopo.html .

CASALES, Fernando (2007): «La América Hispana en el Diccionario panhispánico de dudas: reflexión sobre el uso de algunas preposiciones», en Memorias de las VI Jornadas de Investigación Literaria y Lingüistica: Ana Mireya Uzcátegui, celebradas en Maracaibo, Venezuela, del 25 al 28 de septiembre de 2007. $<$ http://www.ucm.es/info/especulo/numero38/panhispa.htmll .

CORPES XXI: REAL ACADEMIA ESPAÑOLA: Banco de datos (CORPES XXI) [en línea, versión beta]. Corpus del español del siglo XXI. [16.07.2014] $<$ http://web.frl.es/CORPES/view/inicioExterno.view>.

CORDE: Real ACADEmia Española: Banco de datos (CORDE) [en línea]. Corpus diacrónico del español. [16.07.2014] <http://www.rae.es>.

CORREAS, Gonzalo (1903 [1626]): Arte grande de la lengua castellana compuesto en 1626 por el Maestro Gonzalo Correas, catedrático de Salamanca. Publ. por primera vez el conde de la Viñaza, de la Real Academia Española, Madrid, Fe.

CREA: Real ACADEMIa Española: Banco de datos (CREA) [en línea]. Corpus de referencia del español actual. [16.07.2014] <http://www.rae.es>.

DíAZ-RETG, Enrique (1951): Diccionario de dificultades de la lengua española, Barcelona, Editorial Marín.

DPD: REAL ACADEMIA ESPAÑOLA y ASOCIACIÓN DE ACADEMIAS DE LA LENGUA ESPAÑOLA (2005): Diccionario panhispánico de dudas, Madrid, Santillana. Accesible en http://lema.rae.es/dpd/.

DRAE: ReAl ACADEMIA EsPaÑola (2001): Diccionario de la lengua española, Madrid, Espasa Calpe, 22. ${ }^{\text {a }}$ ed. 
GARCÍA PADRÓN, Dolores (2012a): «La derivación no canónica en los gentilicios españoles», en Gerd Wotjak, Dolores García Padrón y María del Carmen Fumero Pérez, eds., Estudios sobre lengua, cultura y cognición, Frankfurt am Main, Peter Lang, pp. 79-87.

(2012b): «Tipos de alogentilicios y su descripción en los diccionarios académicos españoles», en Antoni Nomdedeu Rull, Esther Forgas Berdet y María Bargalló Escrivá, coords., Avances de lexicografía hispánica, Tarragona, Universitat Rovira i Virgili, 1, pp. 147-154.

y Marcial MORERA (2014): «Gentilicios y lexicografía», Onomázein, 30, en prensa.

GARCÍA SÁNCHEZ, Jairo (2009): «La toponimia en los medios de comunicación españoles en castellano con especial atención a sus libros de estilo», en $<$ www.fomento.es/NR/rdonlyres/CE20EEF5-0293-4A8A-83FB

DA4DB53DB9B9/71711/topomediosespa\%C3\%B1oles.pdf $>$.

Gómez Torrego, Leonardo (2009): «El Diccionario panhispánico de dudas y el Manual de español urgente», en Pilar Fernández Martínez e Ignacio Blanco Alfonso, coords., Diccionarios y libros de estilo, Madrid, Fragua, pp. 11-20.

- (2012): «La trascendencia de algunos cambios normativos en el Diccionario panhispánico de dudas», en Sonia Bailini, Cecilia Campos, Raffaella Odicino, Marjorie Sánchez, eds., Actas del Primer Ciclo 'ADELE' 2011-2012. Curso de formación de profesores de E/LE, Milán, EDUCatt, pp. 7-24.

HAENSCH, Günther y Carlos OMEÑACA (2004): Los diccionarios del español en el siglo $X X I$, Salamanca, Universidad de Salamanca.

HERRERA SANTANA, Juana (2012): «Las marcas sociolingüísticas en los gentilicios y su tratamiento lexicográfico», en Gerd Wotjak, Dolores García Padrón y María del Carmen Fumero Pérez, eds., Estudios sobre lengua, cultura y cognición, Frankfurt am Main, Peter Lang, pp. 111-119.

MartíneZ De Sousa, José (2005): «El Diccionario panhispánico de dudas, ¿cumple con su deber?», <http://www.martinezdesousa.net/a-dpd.pdf>.

(2007): Manual de Estilo de la Lengua Española, Gijón, Trea.

MorerA, Marcial (2011): El género gramatical español desde el punto de vista semántico, Frankfurt am Main, Peter Lang, pp. 95-125.

(2012a): «El concepto de gentilicio», en Mar Campos Souto, Ramón Mariño Paz, José Ignacio Pérez Pascual y Antonio Rifón Sánchez, eds., "Assí como es de suso dicho». Estudios de morfología y léxico en homenaje a Jesús Pena, San Millán de la Cogolla, Cilengua, pp. 355-364.

(2012b): «La ampliación designativa de los gentilicios», en Gerd Wotjak, Dolores García Padrón y María del Carmen Fumero Pérez, eds., Estudios sobre lengua, cultura y cognición, Frankfurt am Main, Peter Lang, pp. 177-186.

NeBRIJA, Elio Antonio de (1984 [1492]): Gramática de la lengua castellana, ed. de Antonio Quilis, Madrid, Ed. Nacional.

OrEllanA, Francisco José (1891): Cizaña del lenguaje: Vocabulario de disparates, extranjerismos, barbarismos y demás corruptelas, pedanterías y desatinos introducidos en la lengua castellana (Q.E.P.D.) recopilados de muchos periódicos políticos y literarios, novelas y libros más o menos científicos, discursos académicos y parlamentarios, documentos oficiales y anuncios particulares, Barcelona,Librería de Antonio Bartinos. 
ORTÚZAR, Camilo (1893): Diccionario manual de locuciones viciosas y de correcciones de lenguaje con indicación del valor de algunas palabras y ciertas nociones gramaticales, Imprenta Salesiana.

PÉREZ-SAlAZAR RESANO, Carmela (2008): «Pluralidad de normas en el Diccionario Panhispánico de Dudas», Español Actual, 89, pp. 58-79.

REAl ACADEMia EsPañola (1726-1739): Diccionario de la lengua castellana, en que se explica el verdadero sentido de las voces, su naturaleza y calidad, con las phrases o modos de hablar, los proverbios o refranes, y otras cosas convenientes al uso de la lengua, Madrid, Imprenta de Francisco del Hierro.

REYES MARTÍN, Juan (1918): Serie de barbarismos, solecismos, aldeanismos y provincialismos que se refieren especialmente al vulgo tinerfeño, coleccionados y traducidos al lenguaje corriente con notas explicativas y comprobativas, Santa Cruz de Tenerife.

SAN PEDRO, Benito de (1769): Arte del Romance Castellano, Valencia, Benito Monfort.

SECO, Manuel (1961): Diccionario de dudas y dificultades de la lengua española, Madrid, Aguilar.

TERREROS Y PANDO, Esteban (1786-1793): Diccionario castellano con las voces de ciencias y artes, Madrid, Imprenta de la Viuda de Ibarra.

VERGARA SiLVA, Juan Carlos (2005): «Diccionario panhispánico de dudas. Un paso más en la romería de la lengua», Boletín de la Academia colombiana, 56, 229-230, pp. 144-148. 